\title{
Robust SARS-CoV-2-specific T cell immunity is maintained at 6 months following primary infection
}

\author{
Jianmin Zuo $\mathbb{1}^{1,10}$, Alexander C. Dowell ${ }^{1,10}$, Hayden Pearce ${ }^{1}{ }^{1,10}$, Kriti Verma ${ }^{1,10}$, Heather M. Long ${ }^{1}$, \\ Jusnara Begum', Felicity Aiano², Zahin Amin-Chowdhury², Katja Hoschler², Tim Brooks ${ }^{3}$, \\ Stephen Taylor ${ }^{3}$, Jacqueline Hewson ${ }^{2}$, Bassam Hallis ${ }^{3}$, Lorrain Stapley ${ }^{3}$, Ray Borrow ${ }^{4}$, Ezra Linley ${ }^{4}$, \\ Shazaad Ahmad ${ }^{5}$, Ben Parker,6, Alex Horsley ${ }^{6,8}$, Gayatri Amirthalingam², Kevin Brown², \\ Mary E. Ramsay², Shamez Ladhani ${ }^{2,9,11 \bowtie}$ and Paul Moss $\mathbb{1}^{1,11 \bowtie}$
}

\begin{abstract}
The immune response to SARS-CoV-2 is critical in controlling disease, but there is concern that waning immunity may predispose to reinfection. We analyzed the magnitude and phenotype of the SARS-CoV-2-specific $T$ cell response in 100 donors at 6 months following infection. T cell responses were present by ELISPOT and/or intracellular cytokine staining analysis in all donors and characterized by predominant $\mathrm{CD4}^{+} \mathrm{T}$ cell responses with strong interleukin (IL)- 2 cytokine expression. Median $\mathrm{T}$ cell responses were $50 \%$ higher in donors who had experienced a symptomatic infection, indicating that the severity of primary infection establishes a 'set point' for cellular immunity. $T$ cell responses to spike and nucleoprotein/membrane proteins were correlated with peak antibody levels. Furthermore, higher levels of nucleoprotein-specific $T$ cells were associated with preservation of nucleoprotein-specific antibody level although no such correlation was observed in relation to spike-specific responses. In conclusion, our data are reassuring that functional SARS-CoV-2-specific T cell responses are retained at 6 months following infection.
\end{abstract}

T he SARS-CoV-2 pandemic has led to over 2 million deaths to date and there is an urgent need for an effective vaccine ${ }^{1}$. There is considerable interest in understanding how adaptive immune responses act to control acute infection and provide protection from reinfection. Antibody responses against SARS-CoV-2 are characterized by responses against a range of viral proteins, including the spike, nucleoprotein and membrane proteins. Antibody levels do decline after clearance of primary infection and there is currently considerable interest in the relative maintenance of humoral responses over the longer term. Although initial analyses had shown loss of detectable virus-specific antibodies in a proportion of individuals, highly sensitive ELISAs can demonstrate detectable antibodies for at least 6-7 months in most people ${ }^{2-8}$. Information derived from study of immunity to related viruses such as SARS-CoV-1 and Middle East Respiratory Syndrome ${ }^{9}$ has shown that cellular immune responses against these viruses are maintained for longer periods of time compared to antibody responses ${ }^{10,11}$. This has led to the hope that cellular responses to SARS-CoV-2 will similarly be of more prolonged duration ${ }^{12,13}$.

Studies to date have shown that virus-specific cellular responses develop in virtually all patients with confirmed SARS-CoV-2 infection $^{14}$. These responses remain detectable for several weeks following infection but it is currently unknown how they are maintained thereafter ${ }^{15}$. In this study we characterized SARS-CoV-2-specific
$\mathrm{T}$ cell immune responses in a cohort of 100 donors at 6 months after infection.

\section{Results}

Characteristics of enrolled donors in the study. Blood samples were obtained from 100 convalescent donors at 6 months following initial SARS-CoV-2 infection between March and April 2020. Among the 100 donors, 77 (77\%) were female and 23 (23\%) were male with a median age of 41.5 years (22-65 years). None of the donors required hospitalization at any time during the course of the study. Fifty-six (45 female and 11 male) of the 100 donors who experienced clinical symptoms of respiratory illness were grouped as 'symptomatic' and 44 (32 female and 12 male) who did not experience any respiratory illness were grouped as 'asymptomatic'. There was no significant difference between the median age of the symptomatic (42.5 (23-62) years) and asymptomatic donors (40 (22-65) years). The characteristics of all the patients was summarized in Supplementary Table.

T cell responses against SARS-CoV-2 are present in all donors. Interferon (IFN)- $\gamma$ ELISPOT analysis was used to determine the magnitude of the global SARS-CoV-2-specific T cell response. Peptide pools from a range of viral proteins, including spike, nucleoprotein and membrane protein, were used to stimulate fresh

IInstitute of Immunology and Immunotherapy, University of Birmingham, Birmingham, UK. ${ }^{2}$ Immunisation and Countermeasures Division, National Infection Service, London, UK. ${ }^{3}$ Immunoassay Laboratory, National Infection Service, Porton Down, UK. ${ }^{4}$ Sero-epidemiology Unit, Public Health England, Public Health Laboratory Manchester, Manchester Medical Microbiology Partnership, Manchester Royal Infirmary, Manchester, UK. ${ }^{5}$ Department of Virology, Manchester Medical Microbiology Partnership, Manchester Foundation Trust, Manchester Academic Health Sciences Centre, Manchester, UK. ${ }^{6}$ The NIHR Manchester Clinical Research Facility, Manchester University NHS Foundation Trust, Manchester, UK. 'Kellgren Centre for Rheumatology, NIHR Manchester Biomedical Research Centre, Manchester University NHS Foundation Trust, Manchester, UK. ${ }^{8}$ Division of Infection, Immunity and Respiratory Medicine, University of Manchester, Manchester, UK. 'P Paediatric Infectious Diseases Research Group (PIDRG), St. Georges University of London (SGUL), London, UK. ${ }^{10}$ These authors contributed equally: Jianmin Zuo, Alexander C. Dowell, Hayden Pearce, Kriti Verma. "These authors jointly supervised this work: Shamez Ladhani, Paul Moss. $\varpi_{e}$-mail: Shamez.Ladhani@phe.gov.uk; P.Moss@bham.ac.uk 

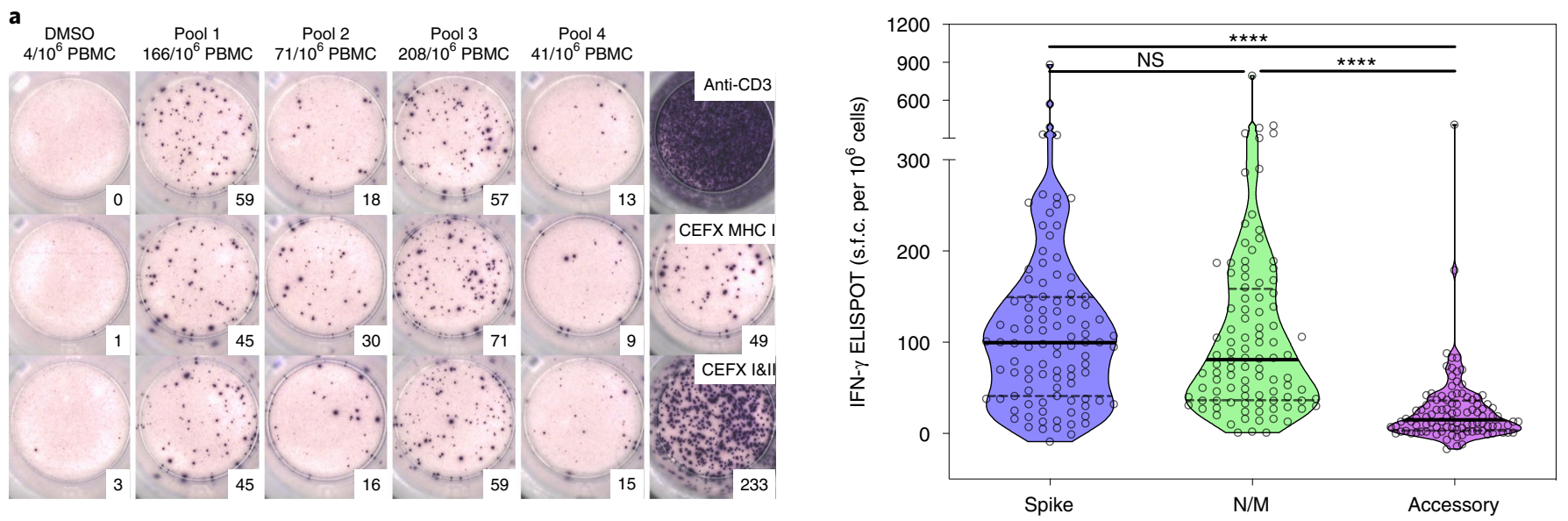

b

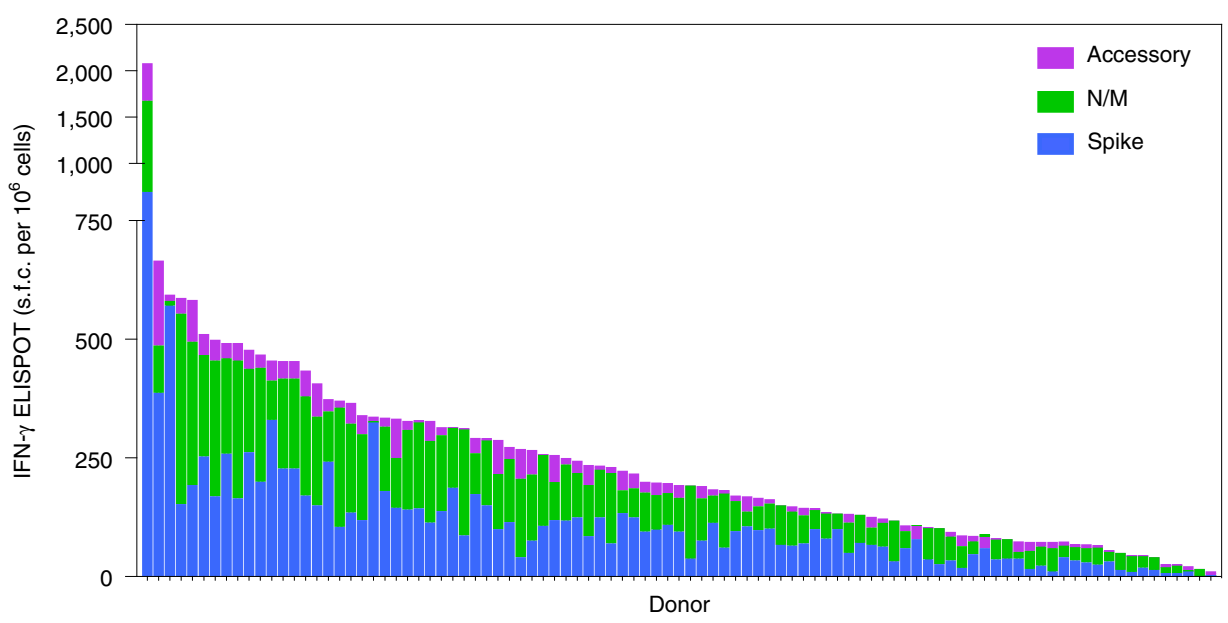

Fig. 1 | Robust T cell immunity against SARS-CoV-2 is present in all donors at 6 months following primary infection. a, ELISPOT responses against SARS-CoV-2 protein pools at 6 months following primary infection. A representative ELISPOT from 1 of 95 donors against spike (pools 1 and 2), N/M and accessory proteins (ORF3a, ORF10, NSP8, NSP7A/b), with DMSO as negative control and CEFX peptide pools and anti-CD3 as positive controls (left). Summary data of all patients $(n=95)$ studied according to spike, N/M and accessory peptide pools (right). Data in graph represented as s.f.c. per million PBMCs. Each point on violin plot represents a single donor. Bold black line represents the median. The significance between pools was determined using a Friedman test (two-sided) with Dunn's multiple comparison test, ${ }^{\star \star \star \star} P<0.0001$; NS, not significant. DMSO, dimethylsulfoxide; s.f.c., spot-forming cells. b, Aggregate ELISPOT response against SARS-CoV-2 proteins at 6 months following primary infection. The spot numbers were aggregated for individual donors and shown in a bar chart.

peripheral blood mononuclear cells (PBMCs) and the magnitude of the global SARS-CoV-2-specific $\mathrm{T}$ cell response was determined. Median ELISPOT responses against the spike glycoprotein (spike); nucleoprotein and membrane (N/M); and ORF3a, ORF10, NSP8, NSP7A/b (accessory) peptide pools were measured at 1 in $10,000(0.010 \%), 12,500(0.008 \%)$ and $66,666(0.0015 \%)$ PBMCs respectively (Fig. 1a). Using the pre-2020 healthy donor PBMCs (Extended Data Fig. 1) to set the cutoff point, 90 of 95 donors (95\%) demonstrated a SARS-CoV-2-specific T cell response to at least one protein with a median total value of 200 cells per million PBMCs (1 in 5,000) (Fig. 1a). Eighteen donors did not have a demonstrable cellular response to spike and no response to the $\mathrm{N} / \mathrm{M}$ pool was seen in eight individuals. No detectable response to any protein tested was seen in five donors by ELISPOT assay although all these donors responded by parallel intracellular cytokine analysis (Fig. 1b).

Considerable heterogeneity was observed in relation to the magnitude of this response. The global and peptide-specific responses were then assessed in relation to the clinical features at the time of primary infection. Notably, median aggregate ELISPOT responses were $50 \%$ higher in donors who had initially demonstrated symptomatic disease compared to those with asymptomatic infection (Fig. 2a). This profile was consistent against both spike and aggregate N/M proteins, where values were $42 \%$ and $55 \%$ higher, respectively in donors with initial symptomatic infection (Fig. 2b). No association was seen between ELISPOT response and donor age. These data collectively demonstrated that $\mathrm{T}$ cell responses against SARS-CoV-2 can be detected in all donors and are 50\% higher in donors with an initial symptomatic infection.

IL-2 production dominates SARS-CoV-2-specific T cell responses. Intracellular cytokine analysis (Extended Data Fig. 2) was then utilized to assess the specificity and pattern of cytokine production from SARS-CoV-2-specific $\mathrm{CD}^{+}$and $\mathrm{CD}^{+} \mathrm{T}$ cells in 100 donors. Virus-specific cytokine responses were seen in 96 people, including the 5 individuals who had been negative by ELISPOT analysis (Fig. 3a). Notably, $\mathrm{CD}^{+}$virus-specific T cell responses were twice as frequent as $\mathrm{CD}^{+}$responses at this 6-month time point $(0.025 \%$ of $\mathrm{CD}^{+}$pool versus $0.012 \%$ of $\mathrm{CD}^{+}$pool, respectively; Fig. $3 \mathrm{~b}$ ). In particular, mean $\mathrm{CD}^{+}$responses against spike and nonspike 

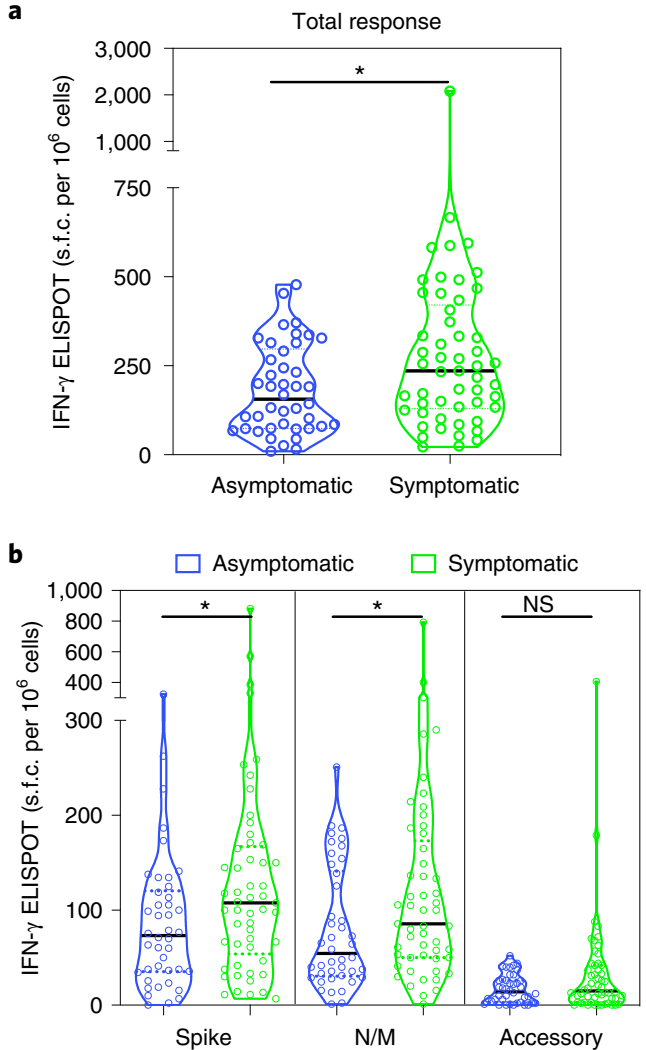

Fig. 2 | T cell responses against SARS-CoV-2 are $50 \%$ higher in donors with an initial symptomatic infection. The cohort was divided into two groups according to symptoms at initial infection. a, The aggregated T cell response (as s.f.c. per million PBMCs) against all peptide pools was compared between patients with $(n=52)$ and without $(n=43)$ respiratory symptoms $(P=0.0235)$. $\mathbf{b}$, T cell responses (as s.f.c. per million PBMCs) to spike (pools 1 and 2$)(P=0.0330), N / M(P=0.0330)$ and accessory proteins $(P=0.2647)$ were compared between patients with and without symptoms. Each point on violin plot represents a single donor. Bold black line represents the median. The significance was determined using a Mann-Whitney U-test (two-sided), ${ }^{\star} P<0.05$.
(N/M/accessory) proteins were measured at $0.009 \%$ and $0.015 \%$ of the $\mathrm{CD}^{+}{ }^{+}$repertoire, respectively, whereas corresponding values for $\mathrm{CD}^{+}$cells were $0.0050 \%$ and $0.0078 \%$ (Fig. 3b). No differences were observed in the virus-specific $\mathrm{CD} 4: \mathrm{CD} 8$ ratio in relation to demographic factors such as age, symptomatic disease or sex.

As expected, the profile of cytokine production differed between the $\mathrm{CD}^{+}$and $\mathrm{CD}^{+}$subsets (Fig. 4a,b). IL-2 responses were dominant within $\mathrm{CD}^{+}$subsets (Fig. $4 \mathrm{~b}$ ) and the pattern of cytokine production by virus-specific $\mathrm{CD} 4^{+} \mathrm{T}$ cells was dependent on antigenic specificity. Single IFN- $\gamma$, single IL-2 and dual positive IL- $2^{+}$IFN- $\gamma^{+}$T cells comprised $0.0016 \%, 0.0052 \%$ and $0.0026 \%$ of the spike-specific $\mathrm{CD}^{+} \mathrm{T}$ cell response, respectively, compared to $0.0017 \%, 0.0105 \%$ and $0.0031 \%$ of the nonspike-specific repertoire (Fig. 4c).

Analysis of the helper $\mathrm{T}\left(\mathrm{T}_{\mathrm{H}}\right)$ cell cytokine profile in the supernatants of overnight ex vivo peptide-stimulated ELISPOT cultures confirmed IL- 2 to be the dominant cytokine released by SARS-CoV2 -specific T cells with variable tumor necrosis factor (TNF) release, alongside IFN- $\gamma$ as detected by ELISPOT. There was no release of cytokines indicative of other $\mathrm{T}_{\mathrm{H}}$ cell subsets including $\mathrm{T}_{\mathrm{H}} 2$ and $\mathrm{T}_{\mathrm{H}} 17$ (Extended Data Fig. 3).

The magnitude of $\mathrm{CD}^{+}{ }^{+} \mathrm{T}$ cell responses against spike and nonspike proteins within each individual was strongly correlated (Fig. 4d); however, this association was less marked for the $\mathrm{CD}^{+}$subset where responses were dominant against nonspike proteins (Fig. 4d).

Altogether, these results suggest that SARS-CoV-2-specific $\mathrm{T}$ cell responses are characterized by a predominant profile of IL-2 production.

The $T$ cell response at 6 months correlates with peak antibody level. We next assessed how the magnitude, phenotype and cytokine profile of the virus-specific cellular immune response at 6 months correlated with the prospective profile of antibody production in the 6 months after infection. Antibody levels against both the spike glycoprotein and nucleoprotein were available at serial time points from all donors (Fig. 5a). These were used to define both the peak value of antibody level against each protein and the rate of decline in antibody level over the subsequent 2 months. Antibody levels fell by approximately $50 \%$ during the 2 months after peak level but stabilized somewhat thereafter although spike-specific responses continued to decline (Fig. 5a). a

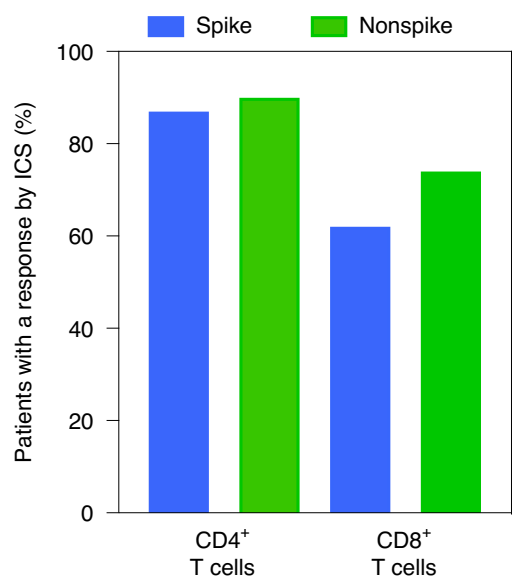

b

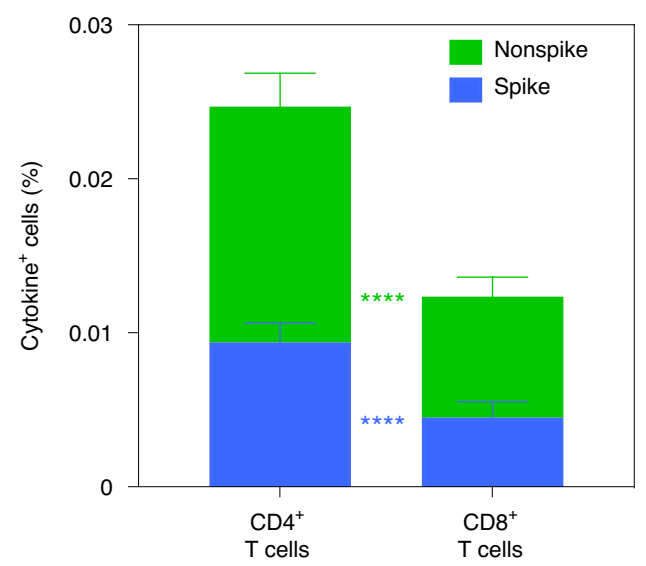

Fig. 3 | Overall detection of SARS-CoV-2-specific T cell responses by ICS. a, Proportion of donors $(n=100)$ with a detectable IFN- $\gamma$ and/or IL-2 response by ICS for CD4+ T cells and CD8 ${ }^{+}$T cells against spike and nonspike proteins 6 months following primary infection. $\mathbf{b}$, Aggregated IFN- $\gamma$ and IL-2 ICS responses for $\mathrm{CD}^{+}$and $\mathrm{CD} 8^{+} \mathrm{T}$ cells against spike and nonspike proteins $(n=100)$. The significance was determined using Wilcoxon matched-pairs signed-rank test (two-sided), ${ }^{\star \star \star \star} P<0.0001$. Error bars represent s.e.m. ICS, intracellular cytokine staining. 

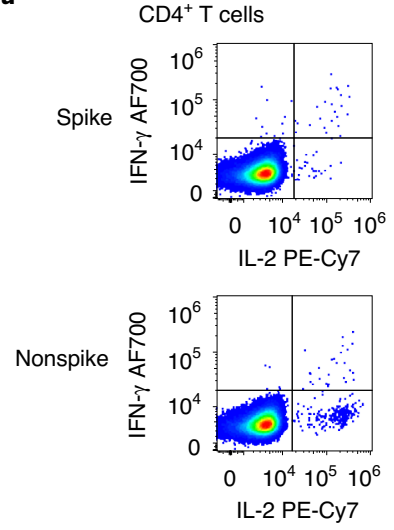

$\mathrm{CD}^{+} \mathrm{T}$ cells
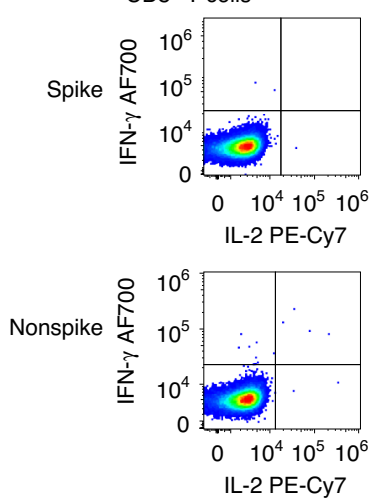
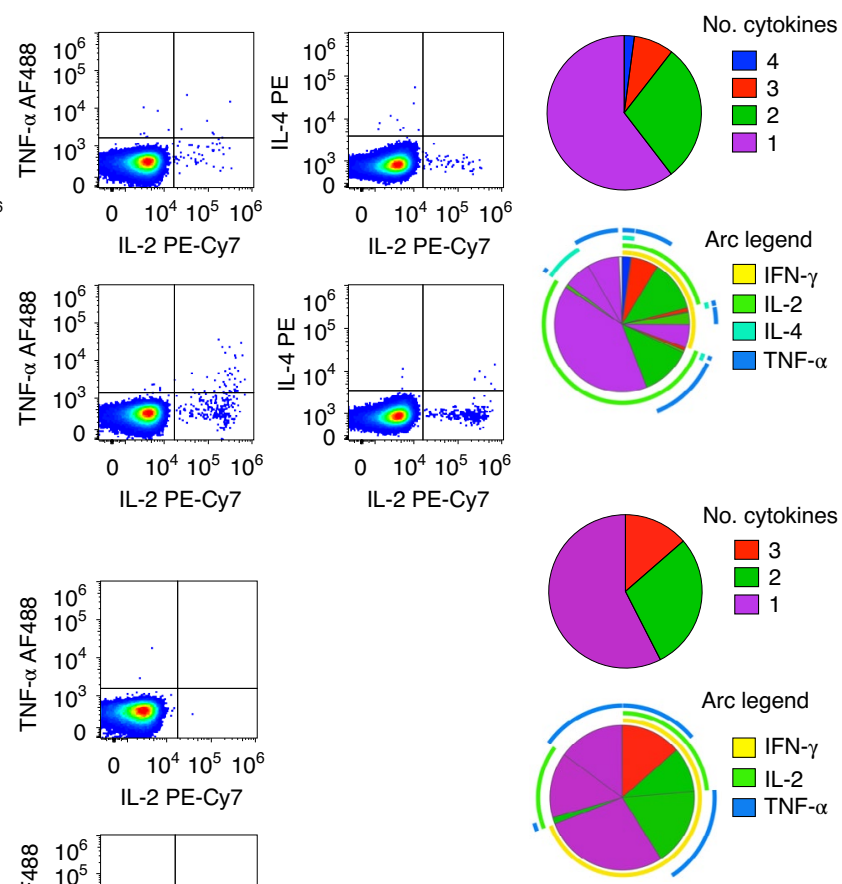
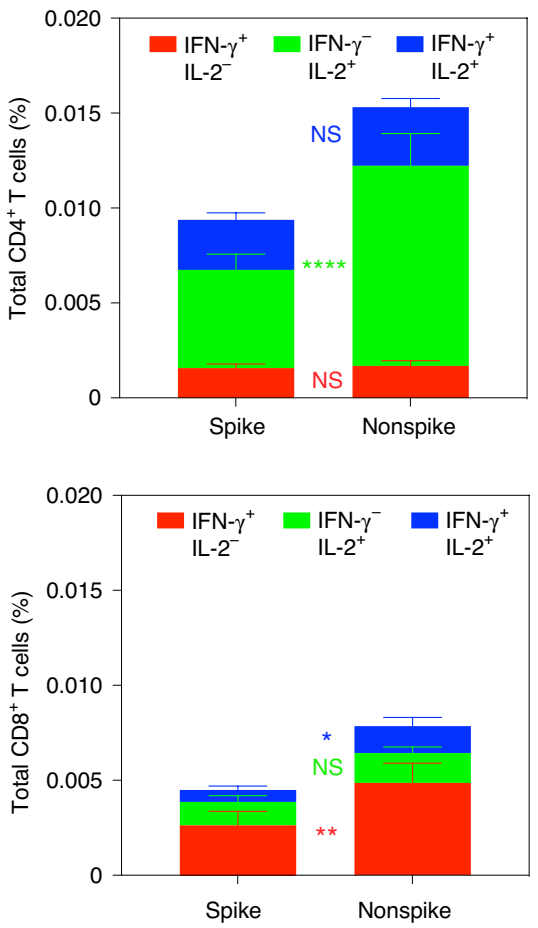

d

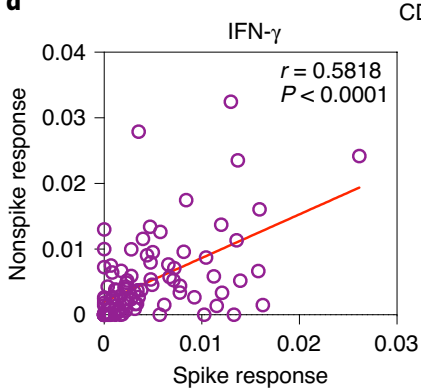

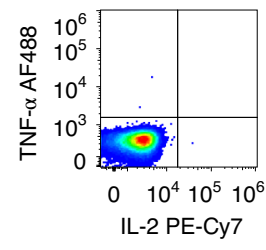

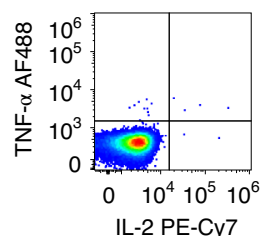

$\mathrm{CD}^{+} \mathrm{T}$ cells

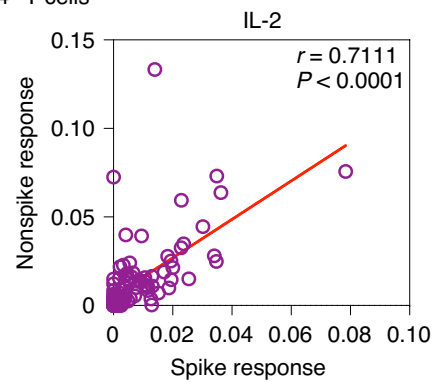

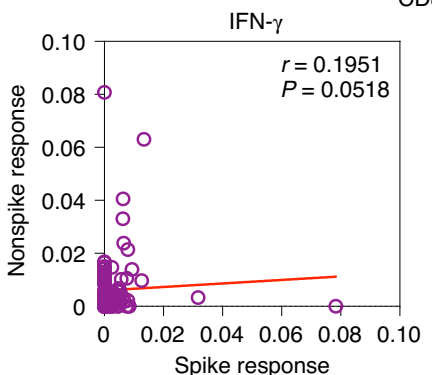

$\mathrm{CD8}^{+} \mathrm{T}$ cells

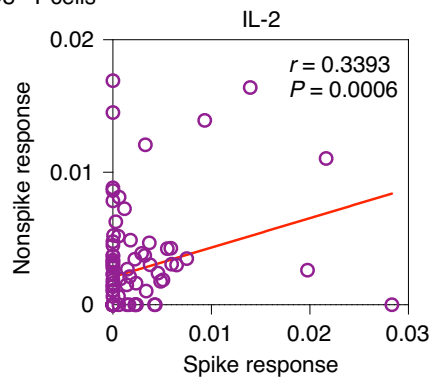

Fig. 4 | SARS-CoV-2-specific T cell responses are characterized by a predominant profile of IL-2 production. a, Features of CD4 ${ }^{+}$and CD ${ }^{+} T$ cell responses against SARS-CoV-2 proteins by ICS at 6 months. Representative flow plots of $C D 4^{+}$(top) and CD8 ${ }^{+}$(bottom) T cell responses against peptide pools from spike or nonspike (aggregate of N, M, ORF3a, ORF10, NSP8 and NSP7A/b) proteins. b, Polyfunctional analysis of SARS-CoV-2-specific CD4+ and CD8+ cells at 6 months. Relative distribution of single or multiple cytokine responses in CD4+ (top) and CD8 ${ }^{+}$(bottom) T cells and pattern of coexpression of IL-2, IFN- $\gamma$, TNF and IL-4 in SARS-CoV-2-specific T cells. c, Aggregate ICS responses for CD4+ and CD8 ${ }^{+}$T cells against spike and nonspike proteins according to IFN- $\gamma$ and/or IL-2 production $(n=100)$. The significance was determined using Wilcoxon matched-pairs signed-rank test (two-sided), ${ }^{\star} P<0.05$, ${ }^{\star \star} P<0.01$, ${ }^{\star \star \star \star} P<0.0001$. The exact $P$ values are: for CD4 ${ }^{+}$T cell and spike versus nonspike, IFN- $\gamma^{+} I \mathrm{~L}-2^{-} P=0.6629 ;$ IFN- $\gamma^{-} \mathrm{IL}-2^{+} P<0.0001$ and IFN- $\gamma^{+} \mathrm{IL}-2^{+} P=0.1536$; for $\mathrm{CD}^{+} \mathrm{T}$ cells spike versus nonspike; IFN- $\gamma^{+} \mathrm{IL}-2^{-} P=0.0036$; IFN- $\gamma^{-} \mathrm{IL}-2^{+} P=0.3071$ and IFN- $\gamma^{+} \mathrm{IL}-2^{+} P=0.0336$. Error bars represent s.e.m. $\mathbf{d}$, Correlation of spike and nonspike responses according to IFN- $\gamma$ and IL-2 production by CD4+ (left) and CD8 ${ }^{+}$(right) T cells at 6 months ( $n=100$ ). Spearman's rank correlation (two-sided) was used to test the significance and $P$ value and $r$ value (correlation coefficient) are indicated for each panel.

The magnitude of the $\mathrm{T}$ cell ELISPOT response at 6 months against the spike protein was strongly correlated with magnitude of the peak antibody level against both spike protein and the receptor-binding domain (RBD) (Fig. 5b). A similar correlation was observed between the cellular response to the N/M pool and the peak level of N-specific antibody (Fig. 5b).

The rate of antibody decline was then assessed in relation to the profile of the cellular immune response at 6 months. Relative preservation of the $\mathrm{N}$-specific antibody response was seen in donors with stronger $\mathrm{N}$ and $\mathrm{M}$-specific $\mathrm{T}$ cell responses at 6 months, suggesting cellular responses may act to support antibody production (Fig. 5c); however, no such association was observed in relation to spike-specific responses.

Finally, we also assessed expression of the chemokine receptor CXCR5, a marker for follicular helper $\mathrm{T}\left(\mathrm{T}_{\mathrm{FH}}\right)$ cells, on virus-specific $\mathrm{T}$ cells and related this to the pattern of stability of the virus-specific antibody response as positive correlations have been observed previously in HIV infection ${ }^{16}$. High numbers of circulating $\mathrm{CD}^{+}$ $\mathrm{T}_{\mathrm{FH}}$ cells have been seen in severe acute infection ${ }^{17}$ but at 6 months CXCR5 was expressed on only $7 \%$ of virus-specific $\mathrm{CD} 4^{+} \mathrm{T}$ cells 

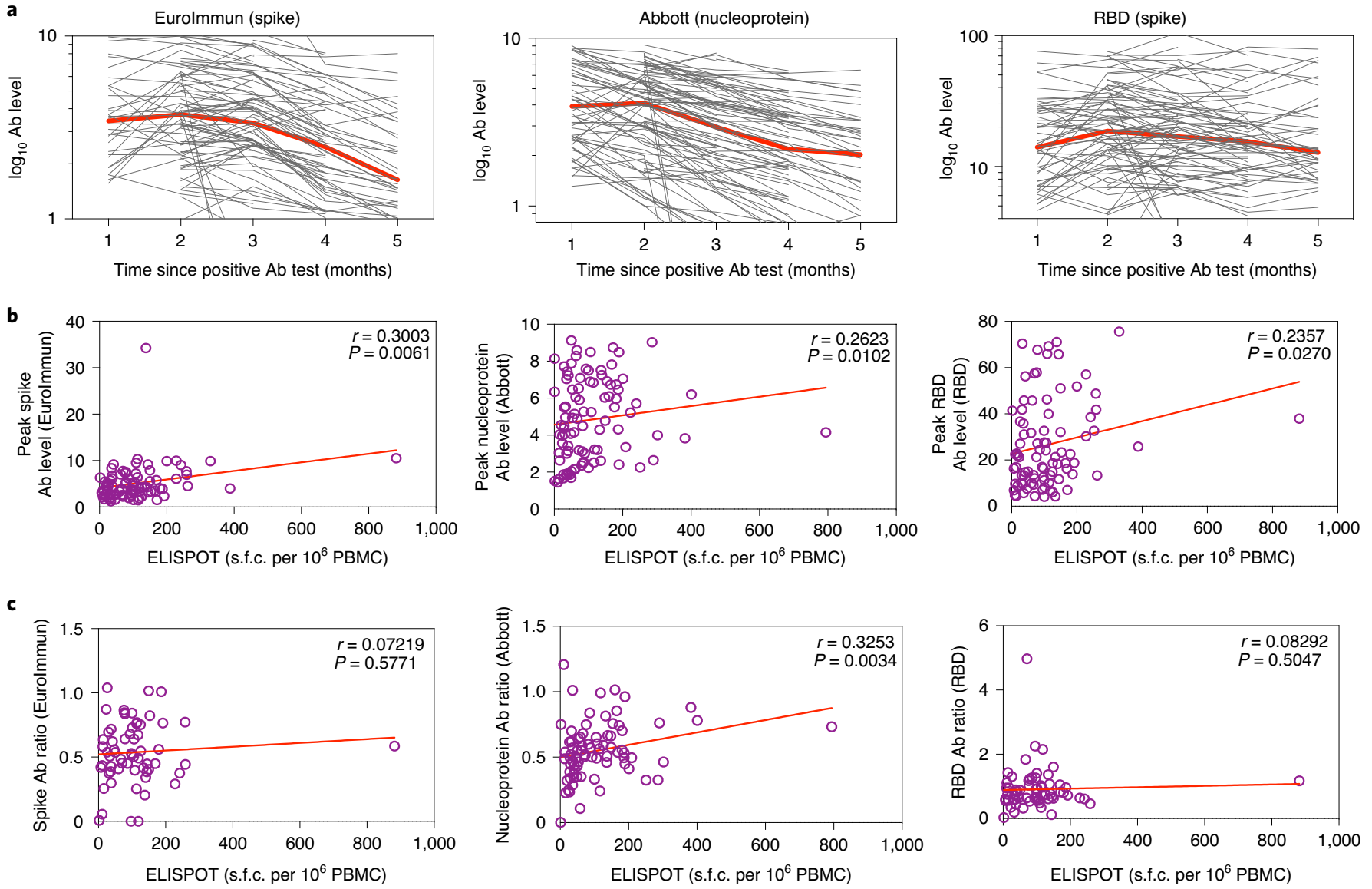

Fig. 5 | The magnitude of the T cell response at 6 months correlates with peak antibody level. a, Antibody levels against spike ( $n=81)$, nucleoprotein $(n=94)$ and RBD $(n=87)$ of all patients at each time point after infection were plotted. Each gray line represents an individual patient. The median antibody (Ab) level over time is shown in red. $\mathbf{b}$, The correlation of ELISPOT responses at 6 months against peak antibody levels (spike, $n=82 ;$ nucleoprotein, $n=94$ and RBD, $n=87$ ) were assessed for each antibody. c, Correlation of ELISPOT responses at 6 months with rate of antibody decline (expressed as ratio of antibody level at 2 months after peak level to antibody peak level) (spike, $n=60$; nucleoprotein, $n=79$ and RBD, $n=67$ ). The line represents linear regression. Spearman's rank correlation (two-sided) was used to test the significance and $P$ value and $r$ value (correlation coefficient) are indicated in each panel.

and no correlation was observed with the profile of antibody level following infection.

The above data demonstrate that the magnitude of the $\mathrm{T}$ cell response at 6 months correlates both with peak antibody level and a reduced rate of antibody waning against nucleoprotein.

\section{Discussion}

The magnitude and quality of the immune memory response to SARS-CoV-2 will be critical in preventing reinfection. Here we undertook an assessment of SARS-CoV-2-specific T cell immune response at 6 months following primary infection in a unique cohort of healthy adults with asymptomatic or mild-to-moderate COVID-19. This clinical group represents the great majority of infections and patients who had been hospitalized with severe disease were not included as they would have been treated with medication such as dexamethasone at the time of acute infection. The major finding was that virus-specific $\mathrm{T}$ cells were detectable in all donors at this extended follow-up period. Approximately 1 in 5,000 PBMCs were SARS-CoV-2-specific, which is broadly comparable to findings within the first 3 months after infection. These values are lower than typical responses against persistent herpesviruses ${ }^{18}$ but comparable to those against acute respiratory viruses, including SARS-CoV-1 (refs. ${ }^{19,20}$ ).

The magnitude of $\mathrm{T}$ cell response was heterogeneous and may reflect diversity in the profile of $\mathrm{T}$ cell immunity during acute infection $^{21}$. A striking feature was that the magnitude of cellular immunity by ELISPOT was $50 \%$ higher in donors who had experienced symptomatic infection. This demonstrates that the initial 'set point' of cellular immunity established following acute infection is maintained for at least 6 months. A similar pattern has been observed early after acute SARS-CoV-2 infection ${ }^{22}$. This is likely to reflect a response to higher viral loads and inflammatory mediators during acute infection ${ }^{23,24}$ although it is also possible that an elevated adaptive immune response during primary infection can itself act as a determinant of clinical phenotype ${ }^{25}$. Cellular responses have a direct protective effect against severe coronavirus infection ${ }^{26}$ and also support antibody production. Indeed, cytokine analysis showed that the $\mathrm{CD} 4^{+} \mathrm{IL}_{-} 2^{+}$subset was most significantly elevated in the symptomatic group.

It was noteworthy that $\mathrm{CD}^{+} \mathrm{T}$ cell responses against SARS-CoV-2 outnumbered $\mathrm{CD}^{+}$effector cells by a ratio of 2 to 1. Again, a similar pattern has been demonstrated at earlier time points after SARS-CoV-2 infection and may reflect high levels of viral protein uptake by antigen-presenting cells and cross presentation to the $\mathrm{CD}^{+} \mathrm{T}$ cell pool or preferential expansion of $\mathrm{CD} 4^{+}$ $\mathrm{T}$ cells $^{27}$. Furthermore, cytokine analysis showed that IL-2 was the major cytokine produced by virus-specific $\mathrm{CD} 4^{+}$cells, indicating a proliferative potential, which may auger well for long-term immune memory ${ }^{28}$. IFN- $\gamma$ responses are broadly equivalent to IL- 2 at early time points after infection ${ }^{29}$ but the profile at 6 months suggests 
that the relative proportion of $\mathrm{T}_{\mathrm{H}} 1$ effector cells decreases over time or they revert to central memory state ${ }^{30}$. Polyfunctional $\mathrm{T}$ cells are typically associated with superior pathogen control $^{31}$ and studies on SARS-CoV-2 infections have revealed decreased cytokine functionality in patients with severe disease ${ }^{22}$. The majority of $\mathrm{CD} 4^{+} \mathrm{T}$ cells at 6 months expressed only a single cytokine and production of three or four cytokines was observed in $<15 \%$ of cells. Of note, the pattern of cytokine production by $\mathrm{CD} 4^{+} \mathrm{T}$ cells varies with protein specificity, as seen in earlier reports ${ }^{22}$. Single IL-2- or IFN- $\gamma$-producing cells were predominant against both spike and structural proteins but the former population was significantly greater in the CD4 $4^{+}$ response against nonspike proteins, indicating that a retained $\mathrm{T}_{\mathrm{H}} 1$ effector profile is more common within the spike-specific pool. The expression of CXCR5 on $\mathrm{CD} 4^{+} \mathrm{T}$ cells has been correlated with the magnitude and persistence of humoral immunity in the setting of HIV infection ${ }^{32}$ but low expression levels on virus-specific $\mathrm{CD}^{+}$ $\mathrm{T}$ cells in our study suggest that circulating virus-specific $\mathrm{T}_{\mathrm{FH}}$ cells are not sustained at high levels after infection. Findings in acute infection have also failed to correlate circulating $\mathrm{T}_{\mathrm{FH}}$ frequencies with the plasmablast response and suggest that non-CXCR $5^{+} \mathrm{CD} 4^{+}$ $\mathrm{T}$ cells may also help ${ }^{21}$. The cytokine profile released by SARS-CoV2 -specific $\mathrm{T}$ cells in ELISPOT supernatants also showed that IL-2 was the dominant cytokine. Notably, low levels of IL-10, IL-4 and TNF were also seen and as IL-10 production is observed within subsets of virus-specific $\mathrm{T}$ cells ${ }^{33,34}$, these represent an interesting population of cells for future investigation.

One of the valuable features of our cohort was the availability of monthly antibody levels against the spike and nucleoprotein in the first 6 months after infection. Serological assays available at the early phase of the pandemic were 'semi-quantitative' and the more recent quantitative methodologies to determine antibody titer will be of interest to further improve data interpretation ${ }^{7}$. Higher $\mathrm{T}$ cell responses at 6 months against N/M proteins correlated with slower decline in $\mathrm{N}$-specific antibody levels and indicate that these antibody responses may be highly $\mathrm{T}$ cell-dependent. In contrast, $\mathrm{T}$ cell responses against spike were not related to the rate of decline of antibodies against that protein, potentially reflecting extracellular protein availability and the strong memory B cell response against spike epitopes ${ }^{35}$. Nevertheless, spike protein-specific cellular responses were present in $>80 \%$ of individuals at 6 months after mild-to-moderate infection and are also recognized as an immunodominant protein following SAR-CoV-1 infection ${ }^{36}$. Spike glycoprotein is the major immunogen used in current vaccine trials and these findings indicate that strong and sustained spike-specific $\mathrm{T}$ cell immunity is likely to be required to sustain immune protection and should be assessed in analysis of optimal vaccine strategies. Our finding that $\mathrm{T}$ cell responses against $\mathrm{M} / \mathrm{N}$ proteins are equally as high as spike responses at 6 months after natural infection suggest that these proteins could also represent valuable components of future vaccine strategies.

Our findings demonstrate that robust cellular immunity against SARS-CoV-2 is likely to be present within the great majority of adults at 6 months following asymptomatic and mild-to-moderate infection. These features are encouraging in relation to the longevity of cellular immunity against this novel virus and are likely to contribute to the relatively low rates of reinfection that have been observed to date ${ }^{37}$. Further studies will be required to assess how these immune responses are maintained over the longer term.

\section{Online content}

Any methods, additional references, Nature Research reporting summaries, source data, extended data, supplementary information, acknowledgements, peer review information; details of author contributions and competing interests; and statements of data and code availability are available at https://doi.org/10.1038/ s41590-021-00902-8.
Received: 1 November 2020; Accepted: 19 February 2021;

Published online: 5 March 2021

\section{References}

1. Huang, C. et al. Clinical features of patients infected with 2019 novel coronavirus in Wuhan, China. Lancet 395, 497-506 (2020).

2. Ibarrondo, F. J. et al. Rapid decay of anti-SARS-CoV-2 antibodies in persons with mild Covid-19. N. Engl. J. Med. 383, 1085-1087 (2020).

3. Long, Q.-X. et al. Clinical and immunological assessment of asymptomatic SARS-CoV-2 infections. Nat. Med. 26, 1200-1204 (2020).

4. Iyer, A. S. et al. Persistence and decay of human antibody responses to the receptor binding domain of SARS-CoV-2 spike protein in COVID-19 patients. Sci. Immunol. 5, eabe0367 (2020).

5. Wajnberg, A. et al. Robust neutralizing antibodies to SARS-CoV-2 infection persist for months. Science 370, 1227-1230 (2020).

6. Ripperger, T. J. et al. Orthogonal SARS-CoV-2 serological assays enable surveillance of low-prevalence communities and reveal durable humoral immunity. Immunity 53, 925-933 (2020).

7. Amanat, F. et al. A serological assay to detect SARS-CoV-2 seroconversion in humans. Nat. Med. 26, 1033-1036 (2020).

8. Figueiredo-Campos, P. et al. Seroprevalence of anti-SARS-CoV-2 antibodies in COVID-19 patients and healthy volunteers up to 6 months post disease onset. Eur. J. Immunol. 50, 2025-2040 (2020).

9. Rabaan, A. A. et al. SARS-CoV-2, SARS-CoV, and MERS-COV: a comparative overview. Infez. Med 28, 174-184 (2020).

10. Payne, D. C. et al. Persistence of antibodies against middle east respiratory syndrome coronavirus. Emerg. Infect. Dis. 22, 1824-1826 (2016).

11. Wu, L.-P. et al. Duration of antibody responses after severe acute respiratory syndrome. Emerg. Infect. Dis. 13, 1562-1564 (2007).

12. Le Bert, N. et al. SARS-CoV-2-specific T cell immunity in cases of COVID-19 and SARS, and uninfected controls. Nature 584, 457-462 (2020).

13. Zhao, J. et al. Recovery from the Middle East respiratory syndrome is associated with antibody and T-cell responses. Sci. Immunol. https://doi. org/10.1126/sciimmunol.aan5393 (2017).

14. Grifoni, A. et al. Targets of T cell responses to SARS-CoV-2 coronavirus in humans with COVID-19 disease and unexposed individuals. Cell 181, 1489-1501 (2020).

15. Reynolds, C. J. et al. Healthcare workers with mild/asymptomatic SARS-CoV-2 infection show $\mathrm{T}$ cell responses and neutralising antibodies after the first wave. Preprint at medRxiv https://doi.org/10.1101/2020.10.13.20211763 (2020).

16. Martin-Gayo, E. et al. Circulating CXCR5 ${ }^{+} \mathrm{CXCR} 3^{+} \mathrm{PD}-1^{\text {lo }} \mathrm{Tfh}-\mathrm{like}$ cells in HIV-1 controllers with neutralizing antibody breadth. JCI Insight 2, e89574 (2017).

17. Meckiff, B. J. et al. Single-cell transcriptomic analysis of SARS-CoV-2 reactive CD4 ${ }^{+}$T cells. Cell https://doi.org/10.2139/ssrn.3641939 (2020).

18. Forner, G. et al. Cytomegalovirus (CMV) enzyme-linked immunosorbent spot assay but not CMV QuantiFERON assay is a novel biomarker to determine risk of congenital CMV infection in pregnant women. J. Clin. Microbiol. 54, 2149 (2016).

19. Savic, M. et al. Epitope specific T-cell responses against influenza A in a healthy population. Immunology 147, 165-177 (2016).

20. Fan, Y.-Y. et al. Characterization of SARS-CoV-specific memory T cells from recovered individuals 4 years after infection. Arch. Virol. 154, 1093-1099 (2009).

21. Mathew, D. et al. Deep immune profiling of COVID-19 patients reveals distinct immunotypes with therapeutic implications. Science 369, eabc8511 (2020).

22. Peng, Y. et al. Broad and strong memory $\mathrm{CD} 4^{+}$and $\mathrm{CD} 8^{+} \mathrm{T}$ cells induced by SARS-CoV-2 in UK convalescent individuals following COVID-19. Nat. Immunol. 21, 1336-1345 (2020).

23. Altmann, D. M. Adaptive immunity to SARS-CoV-2. Oxford Open Immunol. https://doi.org/10.1093/oxfimm/iqaa003 (2020).

24. Zheng, S. et al. Viral load dynamics and disease severity in patients infected with SARS-CoV-2 in Zhejiang province, China, January-March 2020: retrospective cohort study. Brit. Med. J. 369, m1443 (2020).

25. Thieme, C. J. et al. Robust T cell response toward spike, membrane, and nucleocapsid SARS-CoV-2 proteins is not associated with recovery in critical COVID-19 patients. Cell Rep. Med. 1, 100092 (2020).

26. Channappanavar, R., Fett, C., Zhao, J., Meyerholz, D. K. \& Perlman, S. Virus-specific memory CD8 T cells provide substantial protection from lethal severe acute respiratory syndrome coronavirus infection. J. Virol. 88, 11034-11044 (2014).

27. Weiskopf, D. et al. Phenotype and kinetics of SARS-CoV-2-specific T cells in COVID-19 patients with acute respiratory distress syndrome. Sci. Immunol. 5, eabd2071 (2020).

28. Emu, B. et al. Phenotypic, functional, and kinetic parameters associated with apparent T-cell control of human immunodeficiency virus replication in individuals with and without antiretroviral treatment. J. Virol. 79, 14169-14178 (2005). 
29. Rydyznski Moderbacher, C. et al. Antigen-specific adaptive immunity to SARS-CoV-2 in acute COVID-19 and associations with age and disease severity. Cell https://doi.org/10.1016/j.cell.2020.09.038 (2020).

30. Sallusto, F., Geginat, J. \& Lanzavecchia, A. Central memory and effector memory T cell subsets: function, generation, and maintenance. Annu Rev. Immunol. 22, 745-763 (2004).

31. Seder, R. A., Darrah, P. A. \& Roederer, M. T-cell quality in memory and protection: implications for vaccine design. Nat. Rev. Immunol. 8 , 247-258 (2008).

32. Vinuesa, C. G., Linterman, M. A., Yu, D. \& MacLennan, I. C. Follicular helper T cells. Annu Rev. Immunol. 34, 335-368 (2016).

33. Sun, J., Madan, R., Karp, C. L. \& Braciale, T. J. Effector T cells control lung inflammation during acute influenza virus infection by producing IL-10. Nat. Med. 15, 277-284 (2009).
34. Trandem, K., Zhao, J., Fleming, E. \& Perlman, S. Highly activated cytotoxic CD8 T cells express protective IL-10 at the peak of coronavirus-induced encephalitis. J. Immunol. 186, 3642-3652 (2011).

35. Guthmiller, J. J. et al. SARS-CoV-2 infection severity is linked to superior humoral immunity against the spike. mBio 12, e02940-20 (2021).

36. Li, C. K. $-\mathrm{f}$ et al. T cell responses to whole SARS coronavirus in humans. J. Immunol. 181, 5490-5500 (2008).

37. Iwasaki, A. What reinfections mean for COVID-19. Lancet Infect. Dis. https://doi.org/10.1016/S1473-3099(20)30783-0 (2020).

Publisher's note Springer Nature remains neutral with regard to jurisdictional claims in published maps and institutional affiliations.

(c) The Author(s), under exclusive licence to Springer Nature America, Inc. 2021, corrected publication 2021 


\section{Methods}

Ethical statement and clinical definitions. This study was approved by Public Health England (PHE) Research Support and Governance Office (R\&D REGG Ref NR 0190). Donors were recruited from a cohort of staff at PHE that has been monitored for acute infection between March and April 2020. Written informed consent was obtained from all donors. The majority of donors were asymptomatic at the time of initial infection and none was admitted to hospital. All donors were SARS-CoV-2-seropositive using either the EuroImmun, RBD or Abbott test. Serum samples were taken at monthly intervals and assessed by the EuroImmun anti-spike ELISA or the Abbott anti-N assay system. Mean log values were used to determine antibody levels. Cutoff levels for positivity were set at $>0.8$ for the Abbott (N), >5 for RBD (S) and >1.1 for EuroImmun (S) assay as described earlier ${ }^{38}$. Blood samples for cellular analysis were taken at 6 months from the initial PCR-positive test and SARS-CoV-2 seronegative and pre-2020 healthy donor samples were used as controls.

Synthetic peptides. Pepmixes of 15-mer peptides overlapping by 11 amino acid residues covering the major proteins of SARS-CoV-2 (spike glycoprotein (PM-WCPV-S), membrane protein (PM-WCPV-VME), nucleoprotein (PM-WCPVNCAP), ORF3A (PM-WCPV-ORF3A), ORF 7A/B (PM-WCPV-NS7A/7B), ORF10 (PM-WCPV-ORF10) and nonstructural protein 8 (PM-WCPV-NS8); JPT Peptide Technologies). A pool of immunodominant epitopes from common viruses including cytomegalovirus, Epstein-Barr virus and influenza virus (PM-CEFX) was included as positive control (JPT Peptide Technologies).

ELISPOT assay. T cell responses were assessed by ELISPOT assay using a Human IFN- $\gamma$ ELISPOTPro kit (Mabtech) following the manufacturer's instructions. Briefly, freshly isolated PBMCs were rested overnight before assay. Plates were washed with filtered PBS (Sigma Aldrich) and blocked with culture medium containing 10\% batch-tested FBS (Gibco, Thermo Fisher Scientific). As standard, $3 \times 10^{5}$ PBMCs per well were stimulated in triplicate with overlapping peptide pools (JPT Peptide Technologies) at a concentration of $1 \mu \mathrm{g} \mathrm{ml}^{-1}$ of individual peptide for $18 \mathrm{~h}$. In some cases, assays were run in duplicate or with $2.5 \times 10^{6} \mathrm{PBMCs}$ as a minimum. Negative controls comprising DMSO and positive controls, anti-CD3 and CEFX pepmix (JPT Peptide Technologies), were also included. Spots were counted using an AID ELISPOT Reader System (AID). Mean spot counts for negative control wells were subtracted from the mean of test wells to generate normalized readings, these are presented as s.f.c. per million PBMCs. Background levels of response were determined using 12 banked PBMCs taken from healthy donors before 2020 and 6 seronegative PBMCs after 2020. The value of (median $+2 \times$ s.d.) was used as the lower limit to indicate a positive response in the test cohort. This was measured as 32 and 19 spots per million PBMCs for spike and N/M, respectively (Extended Data Fig. 1).

Intracellular cytokine staining. Freshly isolated PBMCs were rested overnight before assay. A total of $1.5 \times 10^{6} \mathrm{PBMCs}$ were stimulated with peptide pools for spike or a combination of NCAP, VME1, ORF10, NS7A, NS7B, AP3A and NS8 at a concentration of $1 \mu \mathrm{g} \mathrm{ml}^{-1}$ of individual peptide for $6 \mathrm{~h}$ in the presence of protein transport inhibitor cocktail (Ebioscience). After incubation, PBMCs were collected and washed before adding fixable red viability dye (Thermo Fisher Scientific) and cell surface antibodies anti-CD3-PerCP5.5 (BioLegend, 1:100 dilution), anti-CD4-APC-Cy7 (BioLegend, 1:40 dilution), anti-CD8-BV510 (BioLegend, 1:40 dilution), anti-PD-1-Pacific Blue (BioLegend, 1:20 dilution) and anti-CXCR5-APC (BioLegend, 1:20 dilution). Staining was performed at $4{ }^{\circ} \mathrm{C}$ for $30 \mathrm{~min}$. Then PBMCs were washed and fixed with Ebioscience IC Fixation buffer at $4{ }^{\circ} \mathrm{C}$ overnight. Following incubation, the fixed cells were permeabilized with $0.1 \%$ Triton-X 100 (Sigma Aldrich) on ice for $30 \mathrm{~min}$, washed with PBS and stained at $4{ }^{\circ} \mathrm{C}$ for $50 \mathrm{~min}$ with intracellular antibodies, anti-TNF-AF488 (BioLegend, 1:20 dilution), anti-IFN- $\gamma$-AF700 (BioLegend, 1:20 dilution), anti-IL-2-PE-Cy7 (BioLegend, 1:20 dilution) and anti-IL-4-PE (BioLegend, 1:20 dilution). All antibodies were purchased from BioLegend. Finally, cells were washed in PBS before analysis on a Gallios Flow cytometer (Beckman Coulter). Negative controls without peptide stimulation were also included for each donor sample. Flow cytometry data were analyzed using FlowJo v.10.7.1 software (FlowJo). Pestle and SPICE software (v.6) was used to determine the frequency of different cytokine response patterns based on all possible combinations ${ }^{39}$.
Supernatant cytokine profile. Following overnight peptide stimulation in ELISPOT assays, $50 \mu \mathrm{l}$ of supernatant was removed and combined from two duplicate wells and cryopreserved at $-80^{\circ} \mathrm{C}$. Supernatant from 11 donors responding in the ELISPOT assay were profiled using a 12-plex Legendplex $\mathrm{T}$ Helper Cytokine Panel v.2 (BioLegend) following manufacturer's instructions. Cytokine beads were analyzed on a BD LSR II flow cytometer (BD Biosciences). Data were analyzed with Legendplex Software (BioLegend) and the average cytokine level was determined from two duplicate samples.

Statistical analysis. Statistical analysis was performed with GraphPad Prism 8 . A two-tailed Mann-Whitney $U$-test was used to compare variables between two groups, a Wilcoxon matched-pairs signed-rank test was used to compare paired nonparametric data and a Friedman test with Dunn's multiple comparisons test was used to compare nonparametric data between more than two groups. Correlations were performed using a Spearman's rank correlation coefficient. Two-way analysis of variance with Dunnett multiple comparisons test was used to determine significance of cytokine profile data. Statistical significance was determined as ${ }^{\star} P<0.05,{ }^{* *} P<0.01,{ }^{* *} P<0.001$ and ${ }^{* * * *} P<0.0001$.

Reporting Summary. Further information on research design is available in the Nature Research Reporting Summary linked to this article.

\section{Data availability}

All raw datasets corresponding to Figs. 1-5 have been uploaded to https://doi. org/10.5281/zenodo.4498304. The processed datasets are available from the corresponding author on reasonable request.

\section{References}

38. Harris, R. J. et al. Serological surveillance of SARS-CoV-2: trends and humoral response in a cohort of public health workers. Preprint at medRxiv https://doi.org/10.1101/2020.10.21.20216689 (2020).

39. Roederer, M., Nozzi, J. L. \& Nason, M. C. SPICE: exploration and analysis of post-cytometric complex multivariate datasets. Cytom. A 79, 167-174 (2011)

\section{Acknowledgements}

The authors would like to thank the staff in the Virus Reference Division at PHE Colindale, who provided testing and contributed to antibody assay development. This work was partly funded by UK Research and Innovation/National Institute for Health Research (NIHR) through the UK Coronavirus Immunology Consortium (UK-CIC). K.V. is supported by Blood Cancer UK (grant no. 17009) and A.D. is supported by the Medical Research Council (grant no. MR/R011230/1). This research was carried out with the support of the NIHR Manchester Clinical Research Facility. B.P. and A.H. are supported by the NIHR Manchester Biomedical Research Centre. The views expressed are those of the authors and not necessarily those of the UK National Health Service, the NIHR or the Department of Health.

\section{Author contributions}

J.Z., A.D., H.P., K.V., H.L. and J.B. performed cellular analyses and data analysis. F.A., Z.A.-C., K.H., L.S., R.B., E.L., S.A., B.P., A.H., G.A., K.B., M.R. and S.L. devised, set up and recruited the ESCAPE cohort. T.B., S.T., J.H. and B.H. performed humoral analyses. S.L., J.Z. and P.M. led on data interpretation and writing of the manuscript. All authors discussed the results and commented on the manuscript.

\section{Competing interests}

The authors declare no competing interests.

\section{Additional information}

Extended data is available for this paper at https://doi.org/10.1038/s41590-021-00902-8.

Supplementary information The online version contains supplementary material available at https://doi.org/10.1038/s41590-021-00902-8.

Correspondence and requests for materials should be addressed to S.L. or P.M.

Peer review information Nature Immunology thanks the anonymous reviewers for their contribution to the peer review of this work. Peer reviewer reports are available. Zoltan Fehervari was the primary editor on this article and managed its editorial process and peer review in collaboration with the rest of the editorial team.

Reprints and permissions information is available at www.nature.com/reprints. 


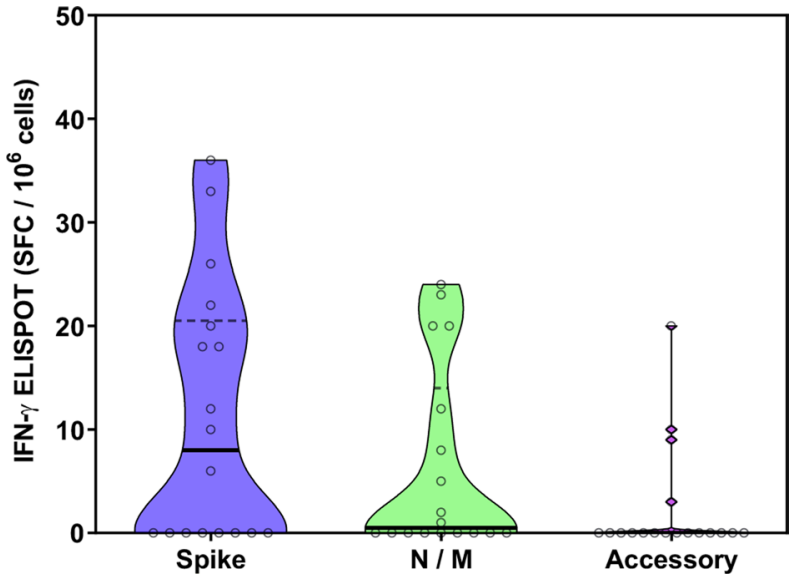

Extended Data Fig. 1 | Set-up of cut-off point for ELISPOT responses against SARS-CoV-2 protein pools using pre-2020 healthy donors PBMC. ELISPOT responses against SARS-CoV-2 protein pools from 17 pre-2020 healthy donors were performed using Spike (pools 1 and 2), N/M and Accessory proteins (ORF3a, ORF10, NSP8, NSP7A/b), with DMSO as negative control. Data in graph represented as SFC per million PBMC. Each point on violin plot represents a single donor. Bold black line represents median. 

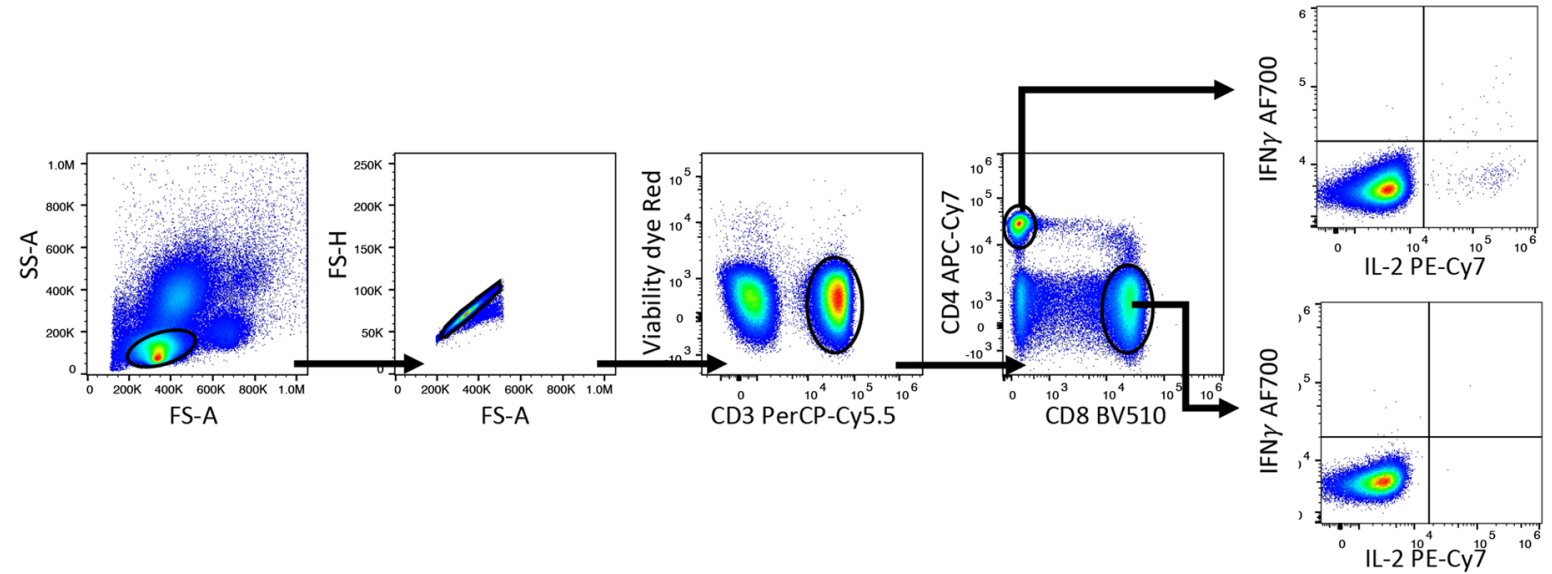

Extended Data Fig. 2 | Gating strategy for Intracellular cytokine staining. First, lymphocytes were gated according to FS-A and SS-A before removing doublets according to FS-A and FS-H. Live T cells were then gated using an amine reactive red fixable viability dye and anti-CD3. Finally, CD4 + and $\mathrm{CD} 8+\mathrm{T}$ cells were gated according to positive staining with anti-CD4 and anti-CD8, respectively. 


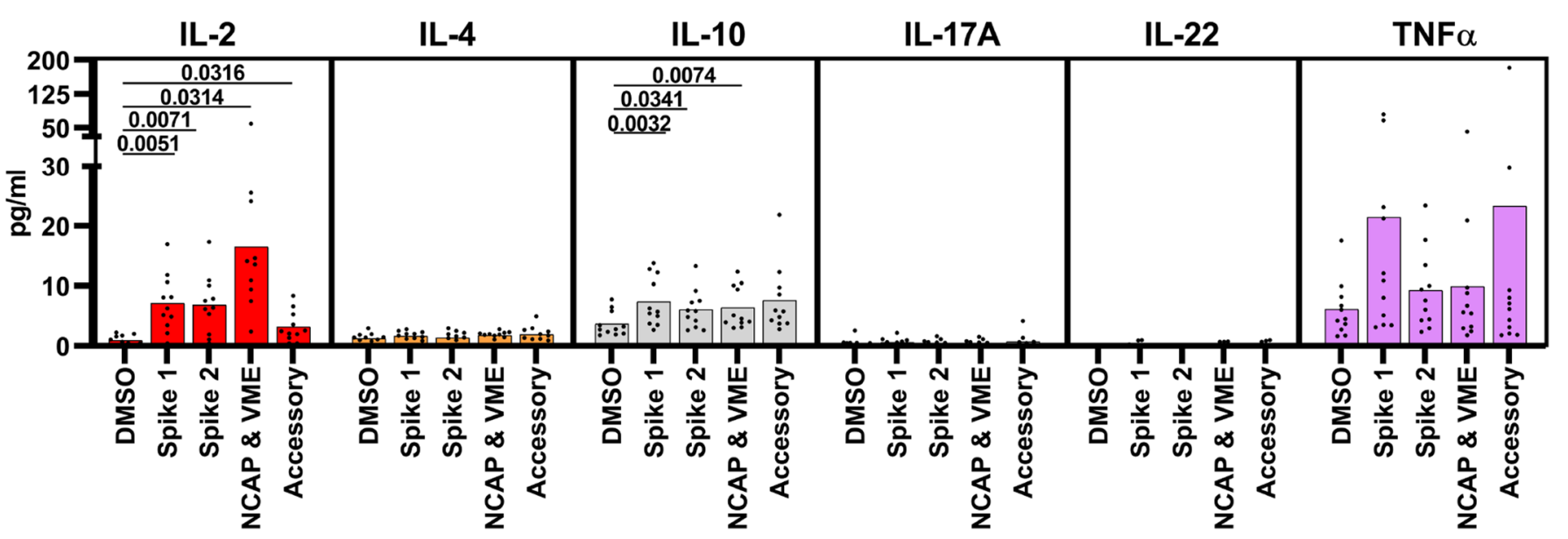

Extended Data Fig. 3 | Characterisation of the Th cytokines released by SARS-CoV-2 specific cells after peptide stimulation. Characterisation of the Th cytokines released by SARS-CoV-2 specific cells during peptide stimulation shows IL-2 is consistently the dominant cytokine released. Supernatant from the wells of ELISPOT assays from eleven responding donors was analysed to assess the release of cytokines representative of classical Th subsets. In addition to the shown, IL-5, -9, -13 and IL-17A/F were not detected. The significance was determined using RM Two-way ANOVA with Geisser-Greenhouse correction, Dunnett multiple comparisons test. 


\section{Reporting Summary}

Nature Research wishes to improve the reproducibility of the work that we publish. This form provides structure for consistency and transparency in reporting. For further information on Nature Research policies, see our Editorial Policies and the Editorial Policy Checklist.

\section{Statistics}

For all statistical analyses, confirm that the following items are present in the figure legend, table legend, main text, or Methods section.

$\mathrm{n} / \mathrm{a}$ Confirmed

$\bigotimes$ The exact sample size $(n)$ for each experimental group/condition, given as a discrete number and unit of measurement

Х $\square$ A statement on whether measurements were taken from distinct samples or whether the same sample was measured repeatedly

The statistical test(s) used AND whether they are one- or two-sided

Only common tests should be described solely by name; describe more complex techniques in the Methods section.

$\bigotimes$ A description of all covariates tested

\ A description of any assumptions or corrections, such as tests of normality and adjustment for multiple comparisons

$\triangle$ A full description of the statistical parameters including central tendency (e.g. means) or other basic estimates (e.g. regression coefficient) AND variation (e.g. standard deviation) or associated estimates of uncertainty (e.g. confidence intervals)

$\triangle$ For null hypothesis testing, the test statistic (e.g. $F, t, r$ ) with confidence intervals, effect sizes, degrees of freedom and $P$ value noted Give $P$ values as exact values whenever suitable.

Х $\square$ For Bayesian analysis, information on the choice of priors and Markov chain Monte Carlo settings

Х $\square$ For hierarchical and complex designs, identification of the appropriate level for tests and full reporting of outcomes

$\square$ Estimates of effect sizes (e.g. Cohen's $d$, Pearson's $r$ ), indicating how they were calculated

Our web collection on statistics for biologists contains articles on many of the points above.

\section{Software and code}

Policy information about availability of computer code

Data collection ELISPOT data was collected using AID ELISPOT Reader System (AID GmbH, Strasberg, Germany)

Flow Cytometry data was acquired using Gallios (BECKMAN COULTER life sciences)

Data analysis Flow cytometry data was analyse using FlowJo - Version 10.7.1

Statistic anaysis was carried out with GraphPad Prism 8.

Cytokines polyfunctional analysis Pestle and SPICE software-version 6

For manuscripts utilizing custom algorithms or software that are central to the research but not yet described in published literature, software must be made available to editors and

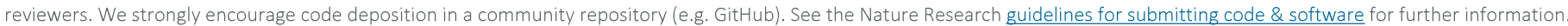

Policy information about availability of data

All manuscripts must include a data availability statement. This statement should provide the following information, where applicable:

- Accession codes, unique identifiers, or web links for publicly available datasets

- A list of figures that have associated raw data

- A description of any restrictions on data availability

All raw datasets corresponding to Figs. 1-5 have been uploaded to http://doi.org/10.5281/zenodo.4498304. The processed datasets are available from the corresponding author on reasonable request. 
Please select the one below that is the best fit for your research. If you are not sure, read the appropriate sections before making your selection.

\ Life sciences

Behavioural \& social sciences

Ecological, evolutionary \& environmental sciences

For a reference copy of the document with all sections, see nature.com/documents/nr-reporting-summary-flat.pdf

\section{Life sciences study design}

All studies must disclose on these points even when the disclosure is negative.

Sample size The sample size was not determined using statistical calculation prior to investigation. This reason for this is the study was in a novel area, with no previous information, and as such the 'effect size' could not be predicted. The ambition was nor $n>100$.

Data exclusions For ELISPOT, donors in which the 'positive control' did not respond were excluded as this indicates potential problem with sample quality and is standard practice.

For ICS, obvious outliers are excluded.

For the antibody level, the data that is lower than cut-off after the onset of disease are excluded. Donors without follow up were also excluded as trajectory of response was an important assessment.

Replication The ELISPOT was carried out in triplicate. The results are always consistent.

The finding was verified each other by two methods in the study: ELISPOT and intracellular cytokines flow cytometry.

Randomization The two groups compared in the study were determined according to symptomatic or asymptomatic.

Blinding The investigators were blinded during the data collection and data analysis.

\section{Reporting for specific materials, systems and methods}

We require information from authors about some types of materials, experimental systems and methods used in many studies. Here, indicate whether each material, system or method listed is relevant to your study. If you are not sure if a list item applies to your research, read the appropriate section before selecting a response.

\begin{tabular}{l|ll} 
Materials \& experimental systems & Methods \\
\hline n/a & Involved in the study & \\
\hline & $\bigotimes$ Antibodies & $\square$ Eukaryotic cell lines \\
$\square$ & $\square$ Palaeontology and archaeology \\
$\square$ & $\square$ Animals and other organisms \\
$\searrow$ & $\square$ Clinical data \\
$\searrow$ & $\square$ Dual use research of concern
\end{tabular}

\section{Antibodies}

Antibodies used

Anti-CD3-PERCP5.5 clone: HIT3a; cat: 300328; lot: B286619, Company: Biolegend, San Diego, CA, US Anti-CD4-APC-Cy7 clone: A161A1; cat: 357416; lot: B299289, Company: Biolegend, San Diego, CA, US Anti-CD8-BV510 clone: SK1, Cat: 344732, lot: B310466, Company: Biolegend, San Diego, CA, US Anti-PD-1-Pacific Blue Clone: EH12.2H7, Cat: 329916, lot: B242234, Company: Biolegend, San Diego, CA, US Anti-CXCR5-APC: clone: J252D4, cat: 356908, lot: B278104, Company: Biolegend, San Diego, CA, US Anti-TNF-a-AF488: clone : MAb11; cat: 502915; lot: B285221, Company: Biolegend, San Diego, CA, US Anti-IFN-AF700: clone: 4S.B3; cat: 502520; lot: B302043, Company: Biolegend, San Diego, CA, US Anti-IL-2_PE-Cy7: clone: MQ1-17H12, Cat: 500326, lot: B314085, Biolegend, San Diego, CA, US Anti-IL-4-PE clone: MP4-25D2, Cat:500810, Lot B267326 Biolegend, San Diego, CA, US

Validation

All the antibodies are commercially available and have been validated by the manufacture. Then they are all titrated in the lab. Validation information can be found on the company's website as shown below.

Anti-CD3-PERCP5.5: https://www.biolegend.com/en-us/products/percp-cyanine5-5-anti-human-cd3-antibody-5613?

GroupID=GROUP28

Anti-CD4-APC-Cy7: https://www.biolegend.com/en-us/products/apc-cyanine7-anti-human-cd4-antibody-13182

Anti-CD8-BV510: https://www.biolegend.com/en-us/products/brilliant-violet-510-anti-human-cd8-antibody-10739

Anti-PD-1-Pacific Blue: https://www.biolegend.com/en-us/products/pacific-blue-anti-human-cd279-pd-1-antibody-6153

Anti-CXCR5-APC: https://www.biolegend.com/en-us/products/apc-anti-human-cd185-cxcr5-antibody-8360

Anti-TNF-a-AF488: https://www.biolegend.com/en-us/products/alexa-fluor-488-anti-human-tnf-alpha-antibody-2750 


\section{Human research participants}

Policy information about studies involving human research participants

Population characteristics

The donors' average age is 41.5 years (22-65 years), 23 male and 77 female. They were tested positive for antibody against COVD-SARS-2 during late March to begining of April 2020.

Recruitment

The donors were staff at health protection agency and HCW and were recruited into a novel cohort in the very early period of the COVID pandemic. They included people with symptomatic disease and those in which seropositive antibody status was observed on screening.

Ethics oversight

This study was approved by Public Health England Research Support and Governance Office (R\&D REGG Ref NR 0190). Donors were recruited from a cohort of staff at Public Health England (PHE) that has been monitored for acute infection in March-April 2020. Written informed consent was obtained from all donors.

Note that full information on the approval of the study protocol must also be provided in the manuscript.

\section{Flow Cytometry}

\section{Plots}

Confirm that:

\The axis labels state the marker and fluorochrome used (e.g. CD4-FITC).

\The axis scales are clearly visible. Include numbers along axes only for bottom left plot of group (a 'group' is an analysis of identical markers).

\All plots are contour plots with outliers or pseudocolor plots.

\A numerical value for number of cells or percentage (with statistics) is provided.

\section{Methodology}

Sample preparation

Instrument

Software

Cell population abundance

Gating strategy
Whole blood were collected in EDTA tubes. The PBMCs were isloated using Ficoll.

Gallios 10 Colors, 3 Lasers, B5-R1-V2 Configuration, B43618

Data was acquired using CXP software and analyzed using FlowJo Version 10.7.1.

The samples were not FACS sorted.

At First, lymphocyte was gated according to FS-A and SS-A before the singlets were gated according to FS-A and FS- $\mathrm{H}$. Then the live CD3+ $T$ cells were gated using live dye and anti-CD3. At last the CD4+ and CD8+ T cells were gated according to CD4 and $C D 8$ expression respectively.

$\bigotimes$ Tick this box to confirm that a figure exemplifying the gating strategy is provided in the Supplementary Information. 